\title{
PELATIHAN PEMBUATAN BIOCHAR DARI SERESAH GAMBUT UNTUK MEMINIMALISIR KEBAKARAN LAHAN DI DESA RASAU JAYA II
}

\author{
Muhammad Rizal'1), Muhammad Ali1), Jaini Fakhrudin'), Danie Indra Yama1), \\ Muflihah Ramadhia'), Adi Marjani Patappa') \\ 1)Teknologi Pertanian, Politeknik Negeri Pontianak, Pontianak, Kalimantan Barat, Indonesia \\ Corresponding author : Muhammad Rizal \\ E-mail : mr_izal@polnep.ac.id
}

Diterima 08 Juli 2021, Direvisi 21 Juli 2021, Disetujui 21 Juli 2021

\begin{abstract}
ABSTRAK
Lahan gambut di Desa Rasau Jaya II relatif luas yang berpotensi untuk dimanfaatkan sebagai lahan pertanian walaupun kondisinya marginal. Petani umumnya membakar lahan tersebut pada musim kemarau untuk meningkatkan kesuburan namun efek negatifnya adalah munculnya titik api dan polusi udara dari asap hasil kebakaran lahan. Oleh karena itu dibutuhkan suatu teknologi agar lahan tersebut dapat dimanfaatkan untuk pertanian dengan risiko yang minimal terhadap lingkungan, seperti pembuatan biochar dengan teknik pembakaran terkontrol dari serasah gambut. Tujuan: (1) Meningkatkan pengetahuan petani mengenai pengelolaan lahan tanpa dibakar dan cara pembuatan biochar, (2) Meningkatkan keterampilan petani dalam pembuatan biochar, (3) Meningkatkan jiwa wirausaha terutama produk biochar. Kegiatan ini menggunakan metode observasi, partisipator dan eksperimental serta survey dengan kegiatan penyuluhan, pelatihan, pembuatan dan aplikasi biochar yang dibuat dari serasah gambut serta evaluasi di Desa Rasau Jaya II. Hasil dari kegiatan tersebut yaitu 97\% peserta mengetahui dampak positif pengelolaan lahan tanpa dibakar dan mengetahui cara pembuatan biochar, $93 \%$ petani sudah terampil dalam membuat biochar, serta $93 \%$ petani juga tertarik untuk mengaplikasikan biochar dalam budidaya tanaman dan menjadikan produk usaha. Kegiatan ini telah meningkatkan pengetahuan, keterampilan dan jiwa wirausaha dalam pertanian khususnya pembuatan biochar dan cukup potensial untuk meningkatkan perekonomian petani cabai di Desa Rasau Jaya serta mengurangi pembakaran hutan dan lahan.
\end{abstract}

Kata kunci: arang; charcoal; histosol; peat.

\begin{abstract}
The peat land in Rasau Jaya II Village are relatively wide which could be used for agriculture potentially even though its in marginal condition. Generally, the farmers would burned the land in the dry season to increase fertility, but the negative effects are emergence of hotspots and air pollution from smoke. Therefore, a technology is needed so that the land can be used for agriculture with minimal risk to the environment, such as making biochar with controlled burning techniques from peat litter or twigs. Objectives: (1) Increase farmers' knowledge about eco-friendly peat land management and how biochar are made, (2) Improve farmers' skills in making biochar, (3) Increase entrepreneurial spirit, especially biochar. This community service activity used observation, participatory and experimental methods as well as surveys with extension activities, training, manufacture and application of biochar made from peat litter as well as evaluation in Rasau Jaya II Village. The results of this activity are that $97 \%$ of participants know about positive impact in peat land management without burning activity wich is relatively new for them , 93\% of farmers are skilled in making biochar, and $93 \%$ of farmers are also interested in applying biochar in plant cultivation and making business products. This activity has increased knowledge, skills and entrepreneurial spirit in agriculture, especially in producing biochar and has the potential to improve the economy of chili farmers in Rasau Jaya Village and reduce forest and land burning activity.
\end{abstract}

Key words: charcoal; charcoal; histosol; peat.

\section{PENDAHULUAN}

Desa Rasau Jaya II terletak di

Kecamatan Rasau Jaya, Kabupaten Kubu Raya, Kalimantan Barat. Luas wilayah desa ini adalah $3630 \mathrm{Ha}$ dengan jumlah penduduk
4.823 jiwa (BPS, 2019). Rata-rata penduduknya memiliki tingkat pendidikan yang rendah dan berprofesi sebagai buruh tani. Selain sebagai buruh tani, sebagian besar penduduk Desa juga menjadi buruh bangunan 
di Kota Pontianak yang lokasinya relatif berdekatan. Hal tersebut dilakukan untuk memenuhi kebutuhan keluarga dan untuk mengantisipasi jika terjadi gagal panen.

Desa Rasau Jaya II dikenal sebagai salah satu daerah dengan potensi gambut yang relatif besar di Kalimantan Barat. Desa ini juga dikenal sebagai penyumbang titik api di Kalimantan Barat yang disebabkan oleh pembakaran oleh masyarakat untuk kegiatan budidaya pertanian. Pembakaran lahan di musim kemarau kerap kali terjadi dikarenakan kebiasaan masyarakat Desa tersebut untuk meningkatkan kesesuaian lahan yang mereka miliki (Gambar 1). Paradigma masyarakat yang menanggap bahwa abu sisa pembakaran dapat menjadi amelioran yang membantu menyuburkan lahan relatif sulit diubah karena sudah mengakar dalam kehidupan masyarakat Desa Rasau Jaya II. Oleh karena itu, masyarakat perlu dikenalkan teknologi lain yang mirip dengan kebiasan mereka namun menimbulkan resiko kerusakan yang lebih kecil.

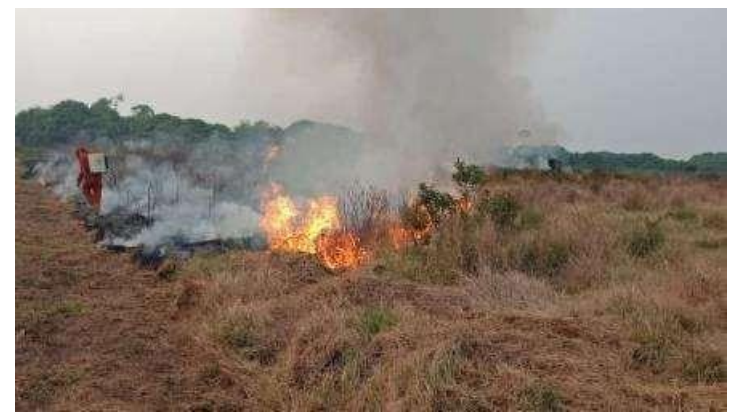

Gambar 1. Lahan di Desa Rasau Jaya II yang Terbakar dan Berusaha Dipadamkan

Lahan yang dimiliki oleh mitra tergolong marginal dan kurang subur sehingga produktivitasnya masih belum optimal. Hal tersebut dikarenakan lahan yang digunakan adalah gambut yang memiliki $\mathrm{pH}$ asam dan pemupukan yang diaplikasikan menjadi tidak optimal. Selain itu, pada lahan gambut juga banyak terdapat ranting, serasah serta sisasisa akar tanaman yang menyebabkan lahan menjadi sukar untuk diolah. Solusi yang saat ini dilakukan petani adalah dengan cara membakar lahan tersebut walaupun sudah terdapat peraturan pelarangan pembakaran lahan. Produktivitas yang rendah memaksa petani di Desa Rasau Jaya II tidak fokus pada bercocok tanam sehingga mereka meninggalkan Desa untuk mencari alternatif pekerjaan di Kota Pontianak sebagai buruh bangunan. Oleh karena itu, mitra perlu diajarkan dan dilatih untuk sistem manajemen dan pemasaran produk yang dihasilkan.
Mitra saat ini masih menerapkan sistem bakar lahan karena sudah mengakar dalam budaya masyarakat untuk melakukan pembakaran lahan sebelum melakukan cocok tanam. Walaupun dari hasil wawancara mitra telah mengetahui bahwa aplikasi kapur dapat meningkatkan $\mathrm{pH}$ dan kesuburan tanah, tetapi metode ini menurut mereka tidak efektif dan efisien. Mitra saat ini sulit dalam mengendalikan api yang menyebar akibat pembakaran yang mereka lakukan dan dihadapkan pada dilema pidana pembukaan lahan dengan cara membakar.

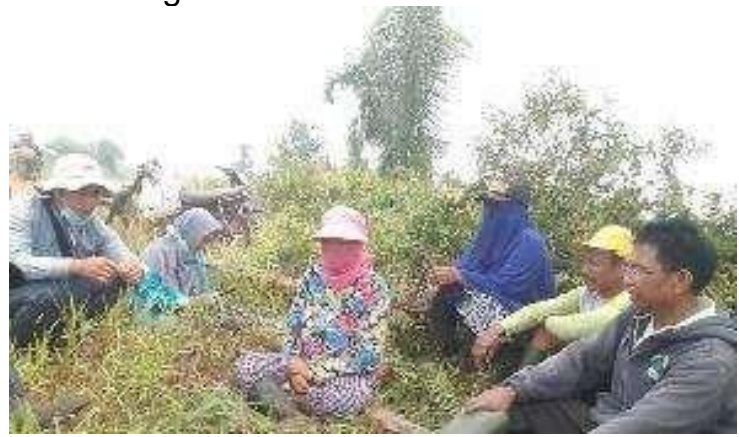

Gambar 2. Kelompok Tani Desa Rasau Jaya II

Salah satu teknologi yang ditawarkan untuk mengatasi permasalahan tersebut adalah konservasi lahan dengan menggunakan biochar yang merupakan hasil pembakaran biomassa dengan menggunakan oksigen dalam jumlah yang sedikit (Gani, 2009). Biochar merupakan substansi arang kayu yang berpori (porous), atau sering disebut charcoal atau agrichar. Karena bahan dasarnya berasal dari makhluk hidup, biochar disebut juga arang aktif. Dalam proses produksi biochar dapat digunakan limbah pertanian atau kehutanan, termasuk potongan kayu, tempurung kelapa, tandan kelapa sawit, tongkol jagung, sekam padi atau kulit biji kacang-kacangan, kulit kayu, sisa usaha perkayuan, dan bahan organik daur ulang lainnya (Gani, 2009). Teknik tersebut sebenarnya sudah dilakukan ribuan tahun yang lalu oleh penduduk suku Maya dan Aztec di pedalaman Amerika Selatan (Adimiharja, 2008). Biochar menghasilkan karbon hingga mencapai $80 \%$ dan mampu meningkatkan kesuburan tanah hingga dua kali lipat walaupun tanpa aplikasi pupuk (Lehmann, et al., 2006). Pembakaran secara pirolisis juga mengeluarkan residu asap yang jauh lebih sedikit jika dibandingkan dengan pembakaran secara langsung sehingga diharapkan dapat menekan bencana kabut asap yang selalu melanda Kalimantan Barat setiap tahunnya (Miles, 2009). Biochar pertama kali dibuat dengan metode pirolisis lambat dimana bahan baku berupa biomassa yang terbakar dalam keadaan oksigen terbatas dengan laju 
pemanasan dan suhu puncak yang relatif rendah (Nurida et al., 2015). Pirolisis merupakan kasus khusus termolisis. Tujuannya adalah melepaskan zat terbang (volatile matter) yang terkandung pada biomassa.

Tujuan dari kegiatan PPM ini adalah meningkatkan pengetahuan petani mengenai pengelolaan lahan tanpa dibakar dan cara pembuatan biochar, meningkatkan keterampilan petani dalam pembuatan biochar, meningkatkan jiwa wirausaha terutama produk biochar. Sedangkan manfaat dari kegiatan PPM ini adalah untuk mengubah perilaku Mitra dalam melakukan pembakaran pada lahan gambut untuk kegiatan budidaya pertanian menjadi pembakaran secara terkontrol yang menghasilkan biochar.

\section{METODE}

Kegiatan PPM dilaksanakan di Kantor Kecamatan Rasau Jaya, Kabupaten Kubu Raya, Kalimantan Barat yang diikuti oleh Karang Taruna dan anggota Tim Waspada Api Desa Rasau Jaya II, Kecamatan Rasau Jaya. Kelompok ini beranggotakan 20 orang yang dikoordinir langsung oleh Kepala Desa. Kelompok ini aktif melaksanakan pertemuan dan diskusi terkait perkembangan pertanian baik dari segi teknis budidaya hingga pemasaran hasil panennya. Kegiatan PPM melibatkan pemimpin daerah setempat yang berkontribusi penting menjadi fasilitator bagi tim pelaksana (UPPM Polnep) dan masyarakat (khalayak sasaran). Tim pelaksana bertugas menyalurkan ipteks sesuai bidang ilmu. Metode yang digunakan dalam kegiatan survey lokasi yaitu observasi langsung, penyuluhan dan pelatihan dilakukan dengan metode partisipator dan eksperimental, sedangkan evaluasi menggunakan metode survey.

\section{Penyuluhan dan Pelatihan}

Penyuluhan dan pelatihan dilakukan di Balai Desa dengan mengundang kelompok tani Desa Rasau Jaya II. Pelatihan dilakukan dengan metode presentasi dan menampilkan bahan tayang/alat peraga. Pelatihan dilakukan untuk sosialisasi manfaat biochar bagi tanaman dan lingkungan, proses pembuatannya, hingga pengaplikasiannya.

\section{Pembuatan Biochar}

Mitra dari kegiatan PPM ini berperan aktif dalam praktek pembuatan dan pengaplikasian biochar. Hasil dari kegiatan ini diharapkan mitra tidak lagi membakar lahan secara langsung, namun menggunakan alat yang telah diberikan yaitu melakukan pembakaran secara terkontrol. Dengan adanya kegiatan ini diharapkan juga mitra dapat ikut mendispersikan teknik pirolisis ini kepada kelompok tani lainnya.

Menurut Nurida et al., (2015), Zalor \& Pyle (1982), dan Lehmann et al. (2006), tahapan pembuatan biochar dilakukan sebagai berikut :

1. Mengumpulkan serasah dari tanah gambut yang akan dijadikan biochar sesuai dengan ukuran drum. Bahan yang di gunakan adalah bahan yang mempunyai kandungan selulosa tinggi (Zaror \& Pyle, 1982).

2. Jemur limbah pertanian tersebut dibawah sinar matahari hingga kering udara.

3. Memasang selinder berongga di bagian tengah drum sebagai tempat menyalakan api.

4. Memasukkan serasah dari tanah gambut ke dalam alat pembakaran/pirolisator tersebut (badan drum).

5. Memasukkan kayu bakar atau bahan lainnya ke dalam rongga di bagian tengah drum, lalu dibakar hingga menjadi bara.

6. Melalui bara api yang ada dalam ronggarongga tersebut, proses pembakaran akan berlangsung merata ke seluruh bagian drum.

7. Kontrol suhu melalui termometer yang dipasang di bagian ujung dan tengah alat.

8. Setelah suhu mencapai lebih dari $200^{\circ} \mathrm{C}$ maka penutup drum dipasang dan seluruh lubang udara di bagian tengah drum.

9. Setelah asap mulai keluar melalui cerobong berarti pembakaran sudah berjalan dengan baik. Setelah 2,0-3,5 jam dan bahan yang dibakar sudah tidak lagi banyak mengeluarkan asap, biochar dikeluarkan dan langsung disemprot air agar tidak menjadi abu atau tidak terjadi pembakaran sempurna.

10. Selanjutnya arang dijemur hingga kering. Hasil pembakaran dapat langsung digunakan sebagai ameliorant tanah. Biochar umumnya mempunyai $\mathrm{pH}$ basa, Corganik dan luas permukaan tinggi.

11. Jika diperlukan biochar digiling hingga berdiameter $<2 \mathrm{~mm}$.

\section{Aplikasi Biochar}

Biochar yang sudah dibuat diaplikasikan sebagai campuran media tanam dalam polybag untuk tanaman sayuran. Aplikasi biochar dilakukan dengan mencampurkannya kedalam media tanam secara merata saat proses persiapan media tanam. Dapat juga diaplikasikan dengan diberikan dalam larikan atau jalur tanaman lalu ditutup dengan tanah dilarik (jalur tanaman), selain itu juga dapat di aplikasikan dengan dibenamkan di lubang tanam. Ukuran lubang tanam sesuai dengan 
dosis biochar yang akan diaplikasikan. Selanjutnya lubang ditutup dengan tanah.

\section{Evaluasi Pelaksanaan PPM}

Untuk memastikan pelaksanaan PPM berjalan dengan lancar dan sesuai dengan tujuan pelaksanaan, maka perlu dilakukan evaluasi. Evaluasi pelaksanaan PPM dilakukan dalam beberapa tahap, yaitu:

1. Evaluasi terhadap inovasi yang terserap sebelum dan sesudah pelaksanaan PPM.

Evaluasi pertama berupa kuesioner yang disebar kepada peserta PPM. Evaluasi ini dilakukan tepat sebelum dan setelah berlangsungnya kegiatan penyuluhan dan pelatihan pembuatan biochar. Tujuan dari evalusi ini adalah untuk mengetahui berapa persen serapan pengetahuan dan keterampilan tentang inovasi setelah peserta mengikuti PPM serta manfaat materi yang diberikan bagi peserta.

2. Evaluasi Keberlanjutan Program

Evaluasi kedua dilakukan dua minggu setelah pelaksanaan PPM. Evaluasi ini bertujuan untuk memastikan keberlangsungan produksi biochar oleh petani agar mengetahui potensi serasah gambut jika digunakan sebagai bahan dasar pembuatan biochar.

3. Evaluasi Lanjutan

Evaluasi ini merupakan evaluasi lanjutan terhadap keberlanjutan dan keberhasilan program. Evaluasi ini bersifat sebagai kontrol terhadap kegiatan produksi biochar serta menjaga terjalinnya silaturahim serta kerjasama dengan kelompok tani di Desa Rasau Jaya setelah kegiatan PPM selesai. Indikator keberhasilan dari kegiatan PPM ini adalah alat pirolisis yang diberikan tetap dioperasikan oleh mitra untuk membuat biochar dan mengurangi pembakaran lahan secara langsung.

\section{HASIL DAN PEMBAHASAN}

Kegiatan yang dilaksanakan dalam PPM ini dibagi menjadi 5 (lima) tahapan dimana semua tahapan tersebut dilaksanakan di Kecamatan Rasau Jaya, Kabupaten Kubu Raya. Tahapan kegiatan yang dilaksanakan berupa koordinasi dengan pihak terkait, penyuluhan tentang biochar dan pembakaran terkontrol, pelatihan pembuatan biochar, aplikasi biochar dalam proses budidaya tanaman, dan evaluasi pelaksanaan. Adapun uraian kegiatan yang telah dilaksanakan tersebut adalah sebagai berikut:

\section{Koordinasi pelaksanaan PPM}

Koordinasi pelaksanaan kegiatan PPM dilakukan oleh tim PPM. Pelaksanaan koordinasi diawali dengan pertemuan secara langsung yang dihadiri oleh Camat Rasau Jaya yaitu Drs. Sutomo di Kantor Kecamatan Rasau Jaya. Pertemuan yang dilakukan bertujuan untuk meminta arahan mengenai jadwal, izin dan peserta kegiatan sesuai judul PPM ini. Dalam survey tersebut juga disepakati bahwa kegiatan PPM dapat dilakukan di Kantor Kecamatan Rasau Jaya dengan peserta yang diatur oleh pihak Kecamatan pada tanggal 13 September 2020. Selain itu wilayah tersebut berpotensi besar dan berpeluang dalam mendukung keberhasilan capaian terhadap transfer teknologi pembuatan biochar dari seresah tanah gambut secara pirolisis serta berpotensi memunculkan wirausaha mandiri dalam bidang pertanian.

\section{Penyuluhan tentang Biochar}

Kegiatan penyuluhan diawali dengan pembukaan dan penjelasan tentang deskripsi serta bahan-bahan yang dapat digunakan dalam pembuatan biochar. Materi penyuluhan yang diberikan meliputi fungsi dan peranan biochar terhadap fisika, biologi, dan kimia serta lingkungan gambut yang digunakan untuk proses budidaya tanaman. Selain itu, kegiatan penyuluhan juga memberikan penekanan pada bahaya pembakaran lahan secara langsung sehingga perlu dilakukan pembakaran secara terkontrol agar mendapatkan efek yang baik untuk budidaya tanaman sekaligus meminimalisir efek negatif kerusakan lingkungan. Peserta antusias dalam mengikuti kegiatan ini, beberapa peserta mengajukan pertanyaan-pertanyaan yang mereka anggap kurang paham.

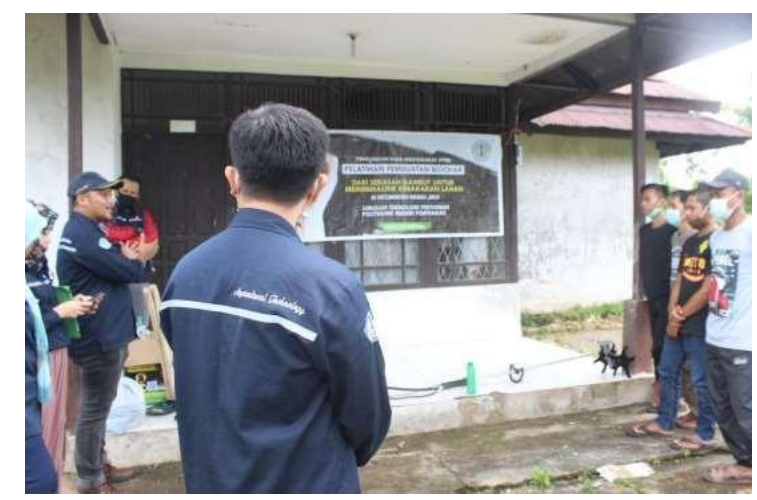

Gambar 3. Kegiatan Penyuluhan secara

Langsung mengenai Biochar dari Serasah Gambut

Penyuluhan dan pembuatan biochar melibatkan karang taruna dan anggota tim waspada api serta tim pengabdian masyarakat Teknologi Pertanian, Politeknik Negeri Pontianak serta pemerintah kecamatan Rasau Jaya (Gambar 4). Keberhasilan kegiatan 
penyuluhan dan pembuatan biochar diukur berdasarkan hasil survey dari peserta yang telah mengisi kuisioner. Gambar 3 merupakan hasil survey mengenai pengetahuan pembuatan biochar setelah dilakukan penyuluhan dan pelatihan pembuatan biochar. Hasil tersebut menunjukkkan terjadi peningkatan pengetahuan peserta mengenai dampak dari pembakaran lahan, biochar serta pemanfaatannya. Hal ini karena semula warga belum pernah mendengar, mengetahui bahkan membuat biochar, mereka sebelumnya selalu beranggapan pembakaran lahan merupakan hal yang praktis dan ekonomis serta abu sisa pembakaran dapat menjadi amelioran yang membantu menyuburkan lahan tanpa melihat efek yang lainnya. Adanya penyuluhan dan pelatihan ini menghasilkan $97 \%$ peserta mengetahui dampak positif pengelolaan lahan tanpa dibakar atau dengan teknologi pembakaran terkontrol dan juga mengetahui cara pembuatan biochar.

Kegiatan ini ditekankan pada dampak negatif dari pembakaran lahan serta manfaat dari biochar. Biochar bersifat ameliorant atau pembenah tanah yang dapat digunakan sebagai pendamping pupuk untuk meningkatkan efisiensi penyerapan pupuk oleh tanaman, menyediakan habitat bagi mikroba tanah, dapat mengikat air dengan baik, dan tidak mengganggu keseimbangan karbonnitrogen dalam tanah. Niochar ini juga lebih efektif dalam renetensi hara dan ketersediaan hara bagi tanaman dibandingkan dengan bahan organik lainnya (Gani, 2009)

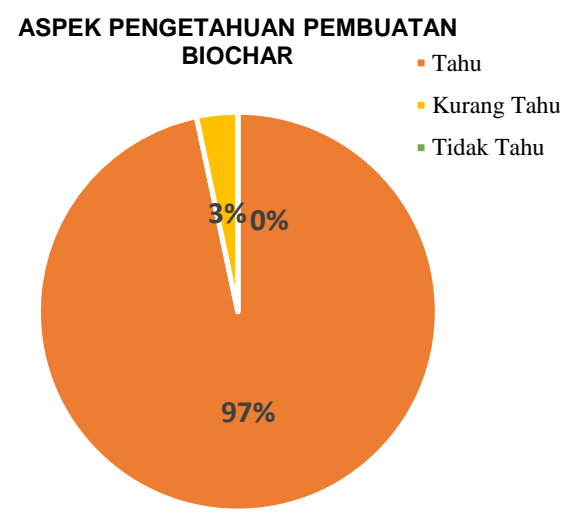

Gambar 4. Tanggapan Peserta terhadap Aspek Pengetahuan Pembuatan Biochar

\section{Pelatihan Pembuatan Biochar}

Pelatihan pembuatan biochar dilakukan secara berkelompok, dari beberapa anggota dibuat beberapa kelompok untuk mempraktikkan pembuatan biochar. Tahapan kegiatan ini dimulai dengan mengambil serasah gambut yang merupakan faktor penghambat bagi pertumbuhan tanaman karena menghasilkan asam organik yang membuat $\mathrm{pH}$ media tanam menjadi asam atau rendah. pengambilan serasah gambut dapat dilakukan secara manual menggunakan cangkul dan parang serta menggunakan alat mekanisasi agar proses pengambilan serasah gambut dapat berjalan efektif dan efisien. Alat mekanisasi yang digunakan untuk mengambil serasah gambut adalah mini tiller yang menggunakan mata traktor rotary yang dipasang pada PTO. Setelah serasah gambut didapatkan, proses selanjutnya adalah pembuatan biochar menggunakan bahan dasar serasah gambut lalu dibakar dengan teknik pirolisis.

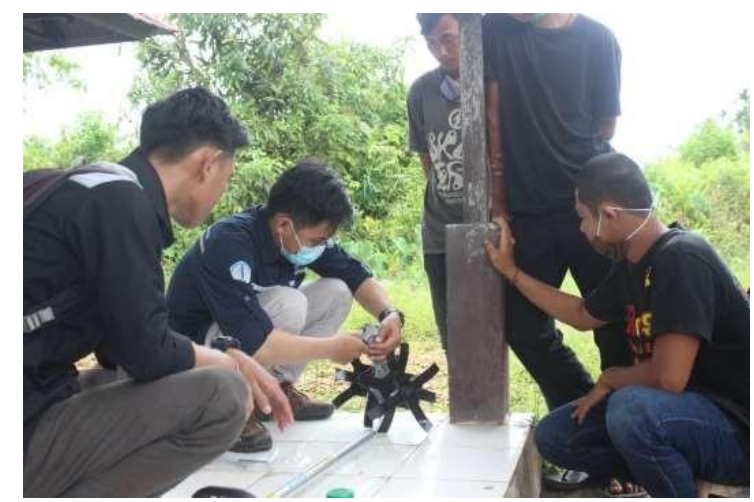

Gambar 5. Pemasangan Traktor Mini Tiller Berjenis Rotary pada PTO

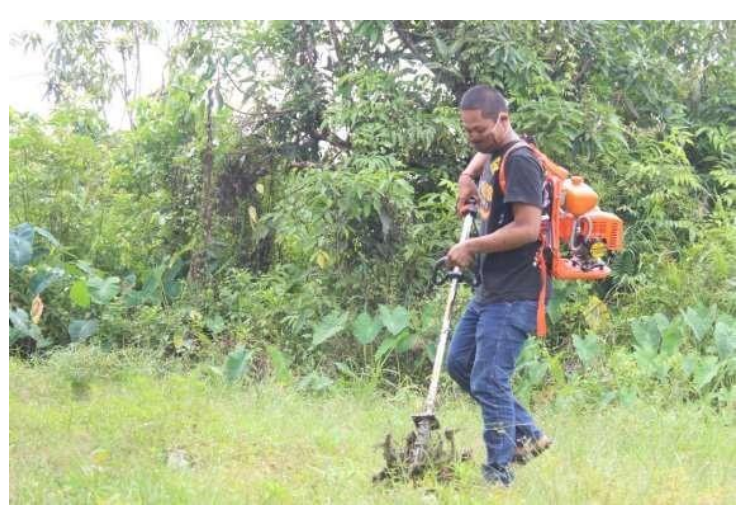

Gambar 6. Simulasi Penggunaan Alat Mekanisasi oleh Peserta PPM Rasau Jaya 
menghasilkan $93 \%$ peserta terampil dalam membuat biochar secara pirolisis, Aspek keterampilan ini dinilai dari beberapa pertanyaan keterampilan pada kuisioner yang sudah diisi oleh peserta. Menurut mereka biochar dapat dibuat sendiri atau bersaman dengan kelompok karena bahan-bahan yang digunakan dapat diperoleh dengan mudah, teknologi yang digunakan juga tidak sulit. Disamping itu terdapat $4 \%$ peserta kurang terampil dan $3 \%$ peserta yang tidak terampil hal ini karena lebih menyukai tindakan yang lebih praktis atau siap pakai seperti memperolehnya dengan cara membeli secara langsung, tetapi mereka tetap menyadari bahwa pengelolaan lahan secara dibakar akan berdampak negatif terhadap tanah, produksi maupun lingkungan.

Kegiatan ini ditekankan pada teknik pembuatan biochar dengan bahan dasar seresah tanah gambut secara pirolisis. Pirolisis adalah sistem pembakaran dengan sedikit atau tanpa oksigen. Biochar dapat dihasilkan dari sistem pirolisis dengan biochar yang dihasilkan sebagian besar dalam keadaan tanpa oksigen dan paling sering dengan sumber panas dari luar. Produksi biochar yang optimal adalah dalam keadaan tanpa oksigen.

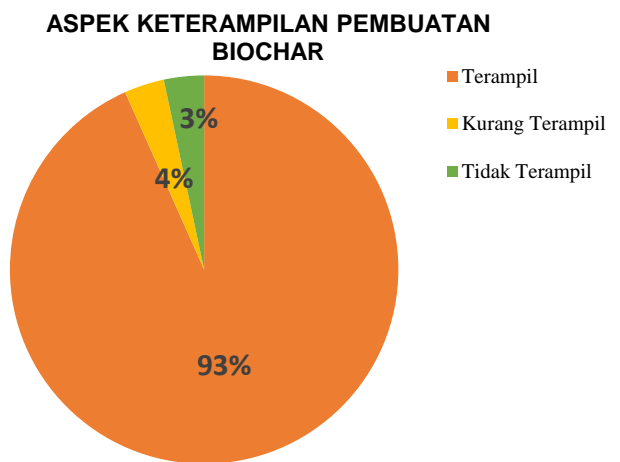

Gambar 7. Tanggapan Peserta terhadap Aspek Keterampilan dalam Pembuatan Biochar

\section{Aplikasi Biochar untuk Budidaya Tanaman}

Biochar yang dihasilkan dari kegiatan sebelumnya pada tahapan ini digunakan sebagai amelioran dan dicampurkan pada media tanam (Gambar 9). Pada kegiatan ini tanaman cabe digunakan sebagai tanaman indikator dalam untuk memberikan bukti kepada masyarakat tentang manfaat biochar bagi tanaman sehingga paradigma masyarakat lebih terbuka untuk melakukan pembakaran secara terkontrol.

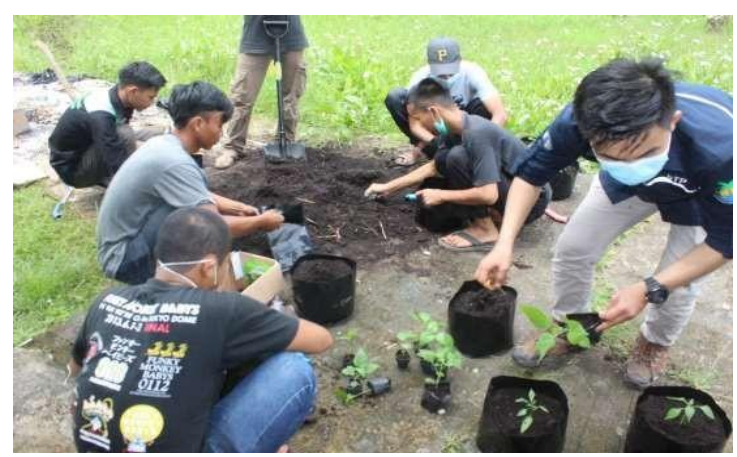

Gambar 8. Proses Penanaman Tanaman Cabe sebagai Indikator

Media tanam yang digunakan untuk budidaya tanaman cabai dicampur dengan biochar dengan perbandingan 1:1 yang dimasukkan kedalam polybag kemudian bibit cabai ditanam pada polybag tersebut dan dipelihara secara normal hingga panen untuk mengetahui pengaruh biochar terhadap pertumbuhan dan produksi tanaman sayuran terutama cabai (Gambar 8).

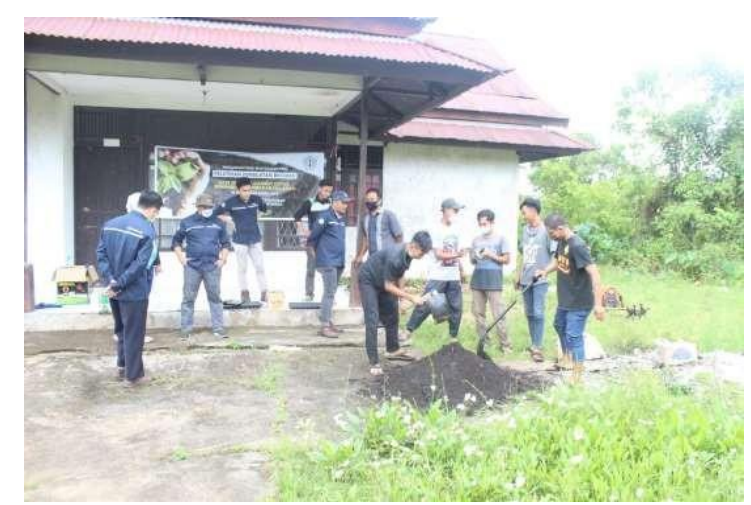

Gambar 9. Proses Pencampuran Media Tanam dengan Biochar

Ketertarikan peserta dalam aplikasi biochar dapat dilihat pada Gambar 10 yang menghasilkan bahwa 93\% peserta tertarik dalam mengaplikasikan biochar. Peserta tertarik untuk membuatnya sendiri serta mengaplikasikan untuk tanaman yang sedang mereka budidayakan. Ketertarikan tersebut didasari oleh pengetahuan akan manfaat biochar terhadap produksi tanaman terutama sayuran. Selain itu karena sifatnya ameliorant maka biochar ini tidak digunakan secara terus menerus dan hanya digunakan saat pengolahan lahan.

Adetiya, dkk, (2017) mengatakan bahwa pemberian biochar cangkang biji karet dan kendega dapat meningkatkan pertumbuhan, jumlah buah dan bobot buah tanaman cabai karena terpenuhinya unsur hara yang dibutuhkan oleh tanaman, dapat menahan air dalam tanah. Indikator keberhasilan dari kegiatan PPM ini adalah 
terjadinya peningkatkan hasil cabai jika dibandingkan dengan kontrol (media tanam tanpa amelioran). Komponen hasil ditunjukkan oleh Bobot buah pertanaman. Pada kegiatan ini penggunaan biochar sebagai amelioran ternyata dapat menyburkan tanaman saat fase vegetatif dan meningkatkan produksi buah cabai hingga $15 \%$.

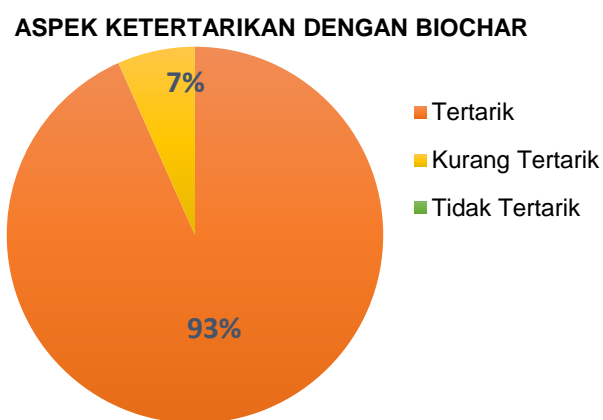

Gambar 10. Tanggapan Peserta terhadap Aspek Ketertarikan dengan Aplikasi Biochar

\section{Evaluasi}

Evaluasi ini merupakan evaluasi lanjutan terhadap keberlanjutan dan keberhasilan program. Evaluasi ini bertujuan untuk melihat keberlanjutan kegiatan pembuatan biochar serta menjaga terjalinnya silaturahim serta kerjasama dengan kelompok tani di Kecamatan Rasau Jaya setelah kegiatan PPM selesai. Tujuan laiinya adalah untuk terus memotivasi petani agar tidak lagi melakukan pembakaran lahan secara langsung melainkan menggunakan metode pirolisis menggunakan alat yang telah diberikan. Harapan laiinya adalah petani dapat membuat sendiri alat tersebut sehingga semakin besar kapasitas produksi yang dihasilkan. Hal ini mendukung masyarakat dalam meningkatkan jiwa kewirausahaan sehingga dapat mengembangkan usaha-usaha yang berguna bagi mira maupun orang lain serta dapat menumbuhkan jiwa yang aktif, kreatif, dan inovatif untuk meningkatkan pendapatan masyarakat.

\section{SIMPULAN DAN SARAN}

Peserta mengalami peningkatan pengetahuan sebesar 97\%, keterampilan pembuatan biochar $93 \%$ dan $93 \%$ ketertarikan dalam aplikasi dan usaha dalam pembuatan biochar dari bahan seresah tanah gambut yang cukup potensial untuk meningkatkan perekonomian petani cabai di Desa Rasau Jaya serta mengurangi pembakaran hutan dan lahan. Perlu adanya pendampingan yang serius kepada kelompok tani (mitra) dalam pengembangan produk biochar agar dapat meningkatkan perekonomian petani.

\section{UCAPAN TERIMAKASIH}

Penulis menyampaikan ucapan terima kasih kepada Politeknik Negeri Pontianak sebagai pemberi dana Pengabdian Pada Masyarakat ini dan telah memberikan dukungan terhadap kegiatan ini sehingga kegiatan Pengabdian Pada Masyarakat dapat terlaksana

\section{DAFTAR RUJUKAN}

Adetiya, N., Sumihar H., Suswati. (2017). Pertumbuhan dan Produksi Tanaman Cabai Merah (Capsicum annum L.) Bermikoriza dengan Aplikasi Biochar dan Pupuk Kimia. Jurnal Agroteknologi dan Ilmu Pertanian. Vol 1(2) : 126-143

[BPS] Badan Pusat Statistik. (2019). Kecamatan Rasau jaya dalam Angka 2019. diakses pada 4 Mei 2020 pada laman http://kuburayakab.bps.go.id.

Gani, Anischan. (2009). Potensi Arang Hayati "Biochar" sebagai Komponen Teknologi Perbaikan Produktivitas Lahan Pertanian. Jurnal Iptek Tanaman Pangan. Vol 4 (1) : 33-48

Adimihardja, Abdurachman. (2008). Teknologi Dan Strategi Konservasi Tanah Dalam Kerangka Revitalisasi Pertanian. Bogor. Jurnal Pengembangan Inovasi Pertanian. Vol 1 (2) : 105-124

Lehmann, J., J. Gaunt, and M. Rondon. (2006). Biochar sequestration in terrestrial ecosystems-a review. Mitigation and Adaptation Strategies for Global Change 11:403-427.

Miles, T. (2009). Use of biochar (charcoal) to replenish soil carbon pools, restore soil fertility and sequester CO2. United Nations Convention to Combat Desertification 4th Session of the Ad Hoc Working Group on Long-term Cooperative Action under the Convention, Poznan 1-10 December 2008.

Nurida, N.L., Achmad R, dan S. Sutono. (2015). Biochar Pembenah Tanah yang Potensil. IAARD Press : Jakarta

Sohi, S., Elisa L., Evelyn K., Roland B. (2009). Biochar, climate change and soil : A review to guide future research. CSIRO Land and Water Science Report : 18346618

Zaror, C.A., \& D.L Pyle. (1982). The pyrolysis of biomass : A general review. Proceedings of the Indian Academy of Sciences Section C : Engineering Sciences. 269 